\title{
Human immunodeficiency virus infection and the rheumatologist
}

\author{
Key words: arthritis, acquired immunodeficiency syndrome.
}

The acquired immunodeficiency syndrome (AIDS) was first described in 1981 and its causal agent, the human immunodeficiency virus (HIV), was identified in 1983. The rapid spread of infection by the virus has made a major impact on many fields of medical practice, now with over 100000 reported cases of AIDS world wide. ${ }^{1}$ In the United Kingdom, since the first AIDS cases were described in 1983, there has been an exponential rise with 1546 cases being reported by July $1988,85 \%$ of these being homosexual men (Communicable Disease Surveillance Centre, personal communication). As the number of infected individuals has risen (8794 reported in the UK by July 1988), so the clinical manifestations of infection are becoming increasingly well recognised. The most important are those representing the development of AIDS, including infection with opportunistic micro-organisms and malignancies such as Kaposi's sarcoma. It now appears, however, that HIV infection may increase the risk of development of other conditions not usually associated with immunodeficiency. Psoriasis occurring in association with AIDS was reported in $1985,{ }^{2}$ and in 1987 Winchester and coworkers from New York reported the co-occurrence of AIDS and Reiter's syndrome. ${ }^{3}$

There are two major reports of aseptic, seronegative arthritis occurring in association with HIV infection, predominantly in male homosexuals. In Winchester's series of 13 patients with Reiter's syndrome, ${ }^{3}$ and in Forster's series from London of nine patients with inflammatory joint disease ${ }^{4}$ joint involvement was generally oligoarticular and asymmetrical involving principally the joints of the lower limbs. In both series joint symptoms were generally severe. In addition, other features associated with arthritis were noted in both series, including urethritis, conjunctivitis, uveitis, stomatitis, and keratoderma blenorrhagica. Notable features of Forster's series were the development of psoriasis for the first time in four patients at the time of onset of arthritis and also spinal pain and stiffness suggestive of spondylitis in four patients, though none had radiological or bone scan abnormalities of the spine or sacroiliac joints. Winchester's series included 11 with Achilles tendinitis, and seven patients in this series had radiological evidence of marginal erosions, features not seen in the London series. Nine of 12 patients tested for HLA-B27 from Winchester's series possessed this antigen; all of three patients tested from Forster's series had B27.

These observations raise important questions: firstly, and possibly most importantly: Is HIV infection a genuine risk factor for the development of arthritis, or is the concurrence of joint and HIV disease coincidental? Full epidemiological studies are required to answer this question. Secondly: If there is an association, what are the roles of micro-organisms and of acquired immunodeficiency in the pathogenesis of arthritis? Difficulties in addressing this question are compounded by the fact that these patients probably represent a heterogeneous group with different pathogenetic mechanisms all ultimately resulting in synovitis.

The relation of arthritis to infection in these patients is of considerable interest. Infection could be important in two ways: either HIV infection may render individuals more susceptible to arthritis induced by other micro-organisms or it may cause synovitis directly. In Winchester's series possible precipitating infections were documented in three patients: enteric infection with Shigella flexneri in two, and in one septic arthritis and septicaemia due to Campylobacter fetus preceded the arthritis. The London group examined their patients particularly for evidence of chlamydial infection. In no case was $C$ trachomatis isolated from the genital tract, and in only one patient was evidence of IgG antibody response to $C$ trachomatis demonstrated. This patient had a past history of Reiter's syndrome and therefore this IgG response may not represent recent infection. Also, patients with HIV infection tend to develop poor antibody responses to new antigens despite the presence of hypergammaglobulinaemia so that serological tests are more difficult to interpret. Recently, evidence of deposition of 
chlamydial antigen in synovium of patients with sexually acquired reactive arthritis has been demonstrated ${ }^{5}$; using the same technique chlamydial antigen could not be demonstrated in synovial biopsy specimens from two patients with HIV infection. Interestingly, the London group have recently reported two patients with arthritis, a history of acute diarrhoea, and serological evidence of recent yersinia infection (one $Y$ pseudotuberculosis, one $Y$ enterocolitica). ${ }^{6}$ Apart from organisms classically associated with reactive arthritis it is also important to consider a pathogenetic role for other organisms, the host response to which may be altered by the presence of HIV infection. Other infections which have been noted to occur at the time of onset of arthritis include oral candidiasis, herpes zoster, and perianal herpes simplex. ${ }^{4}$

The possibility that HIV may be directly involved in the development of synovitis is supported by several observations. A retrovirus related to HIV has been isolated from the synovium of goats with chronic arthritis (caprine arthritis-encephalitis syndrome) ${ }^{7}$ and inoculation of this virus into specific pathogen free goats' kids produces arthritic lesions similar to those of the spontaneous disease. HIV has been isolated from synovial fluid of patients with arthritis, ${ }^{489}$ though this may merely reflect widespread dissemination of the virus. A recent study from Zimbabwe showed an association between HIV and seronegative arthritis in a group of 13 patients. ${ }^{10}$ Arthritis in this series was not associated with HLA-B27, a feature consistent with a virus induced arthropathy.

Many immunological abnormalities are associated with HIV infection, ${ }^{11}$ and these may yield important clues to the pathogenesis of the joint inflammation. Reduction of CD4 helper-inducer lymphocytes suggests that these cells may not be important in the pathogenesis of arthritis; conversely, a relative or absolute increase in CD8 suppressor-cytotoxic lymphocytes suggests that these cells may have an important role. The clinical evidence from Winchester ${ }^{3}$ and Forster ${ }^{4}$ suggests that with progression of HIV disease and the development of more marked immunological abnormalities and AIDS, joint symptoms become persistent and possibly more severe. This is not, however, the experience of other groups. ${ }^{9}$ Interesting studies using the caprine arthritis-encephalitis model indicate that infection with this retrovirus augments concurrent antigen induced arthritis. ${ }^{12}$

Other rheumatic lesions in HIV positive individuals have been reported, in the main anecdotally. Polymyositis may be associated with HIV infection ${ }^{13}$ or with its treatment with azidothymidine. ${ }^{14}$ Cases of Sjögren's syndrome have been described, ${ }^{15}$ though these are not associated with characteristic autoantibody production. ${ }^{16}$ Systemic lupus ery믕. thematosus $^{17}$ and systemic vasculitis ${ }^{18}$ have also: been reported in the presence of HIV infection Autoantibodies have generally not been docuo mented in HIV infection, though raised titres of anticardiolipin antibodies have been reported ${ }^{19}$; the $e^{\overline{5}}$ clinical significance of these is uncertain. The possibility of opportunistic infection causinges rheumatic lesions should always be considered in HIV positive individuals; for example septic arthritis ${ }_{-}^{\circ}$ due to Cryptococcus neoformans ${ }^{20}$ and Sporothrix $\vec{\omega}$ schenckii ${ }^{21}$ have been described as has myositis due to microsporidiosis. ${ }^{22}$ The possibility of malignancy⿳⺈, such as lymphoma causing musculoskeletal symp-t toms should also be borne in mind.

Joint symptoms may be severe in HIV positiveo patients and this poses problems of management. $\mathrm{In}_{0}^{0}$ many cases non-steroidal anti-inflammatory drugs ${ }^{\supset}$ do not control symptoms, ${ }^{34}$ yet treatment with ${ }_{7}$ immunosuppressive agents, such as methotrexate and azathioprine given inadvertently before patientse were known to be HIV positive, has been associated with clinical deterioration and the appearance of Pneumocystis carinii pneumonia and Kaposi's sक्षीcoma. Clearly, immunosuppressive therapy shoutd be avoided in these patients and even the role intra-articular steroid injection is open to question It will be important to evaluate the effect of othero drugs, such as sulphasalazine and antiviral agents, ino the control of rheumatic symptoms.

The development of inflammatory joint disease in $\overrightarrow{\vec{b}}$ HIV positive individuals poses several practica $B$ problems. Firstly, the possibility of HIV infection? should be considered in patients presenting with? seronegative arthritis, especially if they are fromo high risk groups. The London experience is that upe to half of HIV positive patients presenting with arthritis may not be known to have HIV infection previously. ${ }^{6}$ It may therefore be necessary to coun 윽 sel patients appropriately and arrange for HIV antibody testing. Secondly, for the sake of doctorsand laboratory staff great care must be taken over clinical procedures and handling of pathologica $E$. samples including synovial fluid from these patients $N$ The rate of seroconversion following needlestick injury is currently believed to be about $0.5 \%$ (eigh out of 1510 individuals (Communicable Disease ${ }^{\omega}$ Surveillance Centre)). Gloves should be worn where handling material and if there is any doubt biologicaf samples should be treated as potentially infected $\mathbb{\Phi}_{\mathscr{D}}$

We still have much to learn about the clinical manifestations of HIV infection which may present to the rheumatologist. The increasing number of reports of rheumatic symptoms in HIV positive individuals now emerging suggests that such prob气 
lems may be much commoner than hitherto realised. Moreover, rheumatic lesions will be seen increasingly as the HIV epidemic spreads and individual patients survive longer. Now that treatment strategies are becoming established it is time to focus attention on the less critical aspects of HIV infection which, while not life threatening, produce significant morbidity. Presently the rheumatic syndromes seen in association with HIV infection are poorly defined and insufficient evidence exists to classify seronegative arthritis in these individuals. Thus terms such as 'reactive' or 'psoriatic' are probably best avoided. Although musculoskeletal lesions will doubtless cause problems of diagnosis and management, investigation of these lesions may help to elucidate pathogenetic mechanisms and the possible role of immunological, microbiological, and genetic factors in the development of rheumatic disease.

Dept of Rheumatology,

I F ROWE

Westminster Hospital,

A C S KEAT

Page Street,

London SW1P 2AP

\section{References}

1 Anonymous. Acquired immunodeficiency syndrome (AIDS) [Editorial]. Weekly Epidemic Record 1988: 63: 201-5.

2 Johnson T M, Duvic M, Rapini R P, Rios A. AIDS exacerbates psoriasis. $N$ Engl J Med 1985; 313: 1415.

3 Winchester R, Bernstein D H, Fischer H D, Enlow R, Soloman G. The co-occurrence of Reiter's syndrome and acquired immunodeficiency. Ann Intern Med 1987; 106: 19-26.

4 Forster S M, Seifert M H, Keat A C, et al. Inflammatory joint disease and human immunodeficiency virus infection. $\mathrm{Br}$ Med J 1988; 296: 1625-7.

5 Keat A, Thomas B, Dixey J, Osborn M, Sonnex C, TaylorRobinson D. Chlamydia trachomatis and reactive arthritis: the missing link. Lancet 1987; i: 72-4.

6 Rowe I F, Forster S M, Seifert M H, Keat A C S. Rheumatic lesions in individuals with human immunodeficiency virus (HIV) infection. Br J Rheumatol 1988; 27 (suppl 1): 1.

7 Crawford T B, Adams D S, Cheevers W P, Cork L C. Chronic arthritis in goats caused by a retrovirus. Science 1980; 207: 997-9.

8 Withrington $\mathrm{R} \mathrm{H}$, Cornes $\mathrm{P}$, Harris $\mathrm{J} \mathrm{R} \mathrm{W}$, et al. Isolation of human immunodeficiency virus from synovial fluid of a patient with reactive arthritis. $\mathrm{Br}$ Med $J$ 1987; 294: 484.

9 Kaplan G, Prier A, Ziza J M, Chamaret S, Guetard D, Godeau P. Articular manifestations in HIV infected patients. 10 cases. Br J Rheumatol 1988; 27 (suppl 1): 66.

10 Davis P, Stein M, Latif A, Emmanuel J. HIV and polyarthritis. Lancet 1988; i: 936.

11 Seligmann M, Pinching A J, Rosen F S, et al. Immunology of human immunodeficiency virus infection and the acquired immunodeficiency syndrome. An update. Ann Intern Med 1987; 107: $234-42$.

12 Banks K L, Jacobs C A, Michaels F H, Cheevers W P. Lentivirus infection augments concurrent antigen-induced arthritis. Arthritis Rheum 1987; 30: 1046-53.

13 Dalakas M C, Pezeshkpour G H, Gravell M, Sever J L. Polymyositis associated with AIDS retrovirus. JAMA 1986; 256: 2381-3.

14 Bessen L J, Greene J B, Louie E, Seitzman P, Weinberg H. Severe polymyositis-like syndrome associated with zidovudine therapy of AIDS and ARC. $N$ Engl $J$ Med 1988; 318: 708.

15 Ulirsch R C, Jaffe E S. Sjögren's syndrome-like illness associated with the acquired immunodeficiency syndromerelated complex. Hum Pathol 1987; 18: 1063-8.

16 Itescu S, Brancato L, Buxbaum J, Solomon G, Winchester R. Sjögren's syndrome associated with HIV infection. Arthritis Rheum 1988; 31 (suppl): S35.

17 Kopelman R G, Zolla-Pazner S. Association of human immunodeficiency virus infection and auto-immune phenomena. Am J Med 1988; 84: 82-8.

18 Calabrese L H, Yen-Lieberman B, Estes M, Levin K H, Proffitt M R. Systemic necrotizing vasculitis and the human immunodeficiency virus (HIV): an important etiologic relationship? Arthritis Rheum 1988; 31 (suppl): S35.

19 Canoso R T, Zou L I, Groopman J E. Anticardiolipin antibodies associated with HTLV III infection. Br J Haematol 1987; 65: 495-8.

20 Ricciardi D D, Sepkowitz D V, Berkowitz L B, Bienenstock H, Maslow M. Cryptococcal arthritis in a patient with acquired immune deficiency syndrome. Case report and review of the literature. J Rheumatol 1986; 13: 455-8.

21 Lipstein-Kresch E, Isenberg H D, Singer C, Cooke O, Greenwald R A. Disseminated Sporothrix schenckii infection with arthritis in a patient with acquired immunodeficiency syndrome. J Rheumatol 1985; 12: 805-8.

22 Ladford D K, Overman M D, Gonzalvo A, Cali A, Mester S W, Lockey R F. Microsporidiosis myositis in a patient with the acquired immunodeficiency syndrome. Ann Intern Med 1985; 102: 628-30. 